\title{
Juras y celebraciones políticas en el Nuevo Reino de Granada, 1746-1812
}

\author{
Oaths and Political Celebrations \\ in the New Kingdom of Granada, 1746-1812
}

\author{
Orián Jiménez Meneses \\ Universidad Nacional de Colombia \\ Sede Medellín, Colombia \\ (D) orcid.org/0000-0003-1063-9206 \\ ojimenezm@unal.edu.co
}

Resumen: Este artículo analiza los cambios que hubo en la celebración de las juras en el Nuevo Reino de Granada durante el periodo 1746 a 1812 y centra su atención en las juras de Carlos IV y Fernando VII. Después en la segunda mitad del siglo XVIII, las juras sufrieron algunas transformaciones en la apropiación que hicieron de ellas las poblaciones del Nuevo Reino de Granda y tales cambios se reflejaron en una separación de las ceremonias religiosas y civiles. A partir de 1790, con la llegada al trono de Carlos IV, el ceremonial de las juras se estandarizó y se separaron los actos de la Iglesia y los regocijos de la plaza. Ya en 1808, con los sucesos de Bayona, las elites locales buscaron con las juras defender a Fernando VII y obtener privilegios: las aldeas buscaron convertirse en parroquias, los lugares ser erigidos en villas, las villas en ciudades, los cabildos en nuevas provincias y las provincias en Estados soberanos.

Palabras clave: fiestas; juras; crisis política; soberanía; Nuevo Reino de Granada.

Abstract: This article analyzes the changes in the celebration of the oaths in the New Kingdom of Granada between 1746 to 1812, and focuses on those of Carlos IV and Fernando VII. After the second half of the 18th century, the manner in which the oaths were appropriated by the populations of the 
New Kingdom of Granada changed in several ways, and this was reflected in the separation of religious and civil ceremonies. From 1790 onwards, the accession of Carlos IV to the throne saw a standardization of the ceremonial of oaths, and a separation of Church acts and public celebrations. By 1808, following the events in Bayonne, the local elites sought to use the oaths to defend Fernando VII and obtain privileges: villages tried to become parishes, localities into towns, towns into cities, town halls into new provinces and provinces into sovereign states.

Key words: celebrations; oaths; political crisis; sovereignty; New Kingdom of Granada.

Fecha de recepción: 11 de julio de 2016 Fecha de aceptación: 16 de diciembre de 2016

\section{INTRODUCCIÓN}

T a comunicación entre el rey de España y los vasallos de todo el impeLrio se mantenía a través de las instituciones de los cabildos, las gobernaciones y la Real Audiencia. Una de esas autoridades delegadas -el alférez real- reforzaba la lealtad del cuerpo político y de sus miembros mediante mecanismos jurídicos y políticos heredados desde tiempos antiguos: ${ }^{1}$ se trataba de representaciones por medio de juras. ${ }^{2}$ La puesta en escena para hacer presente al rey consistía en fiestas y rituales de reconocimiento, admiración y obediencia, en los que participaban los variados cuerpos y privilegios de

${ }^{1}$ Con respecto a la tradición según la cual en la figura del rey se encarnaban dos cuerpos, el cuerpo natural y el cuerpo político, Ernst Kantorowicz (1985) analiza que en el siglo XVI Edmund Plowden alude en su obra Commentaries or reports a una superioridad del cuerpo político sobre el natural, pues aquel "no solamente es más amplio y extenso" que el cuerpo natural, sino que en él residen realmente fuerzas misteriosas que actúan sobre el cuerpo natural mitigando, e incluso eliminando, todas las imperfecciones de la frágil flaqueza de la naturaleza humana" (p. 21). En efecto, desde los siglos ix y x, los letrados consideraban que existía una relación orgánica -análoga a la del alma y el cuerpo, la cabeza y los miembrosentre el soberano y la comunidad a la que este debía proteger: el rey necesitaba a su pueblo para ejercer su magistratura, velar por la realización de las funciones sociales y cumplir sus actividades de soberano (Duby, 1983, pp. 141-142).

${ }^{2}$ Las investigaciones de Inmaculada Rodríguez Moya y Víctor Mínguez Cornelles (2012); Magali Carrillo e Isidro Venegas (2009) y Daniel Gutiérrez Ardila (2009) han hecho referencia a este asunto.

\section{(ㄷ)(1) $(3$}


la sociedad, y se unía el resto del vecindario. ${ }^{3}$ En el acto de la jura, el alférez real, como cabeza del Ayuntamiento, se ponía de pie en el balcón del edificio del Cabildo o en un tablado dispuesto para tal fin en la Plaza Mayor y arrojaba monedas al aire para que la muchedumbre se lanzara a recogerlas e hiciera memoria de que, a pesar de la ambigüedad de la figura del rey y la lejanía de su persona, aquel era magnánimo y generoso con sus súbditos. Por tratarse de una ceremonia de recibimiento del nuevo soberano, el alférez fungía como el agasajado y depositario de la obediencia y la admiración de las que era merecedor el rey ausente.

En los periodos de transición de los que se ocupa este artículo, los ceremoniales y las formas de celebrar el ascenso al trono de los nuevos monarcas sufrieron algunos cambios: se redujo lo que en tiempos de los Austrias (14691700) y los primeros tiempos de los Borbones (1700-1746) había sido una "religión real" y se aumentó el espectáculo de la fiesta taurina, los torneos y los regocijos de plaza para entretener al pueblo (Calvo, 2005, pp. 67-92). Ya en 1790, el ceremonial de la jura alcanzó mayor estandarización en cuanto a la reducción del tiempo dedicado por las autoridades locales con respecto a las juras de 1747 en las ciudades de Panamá y Popayán; se estableció una separación clara entre los regocijos de plaza y los actos religiosos y, a partir de 1808, se aumentó la frecuencia en la celebración de las juras en todas las poblaciones del virreinato. En esta perspectiva, este artículo analiza el ceremonial de las juras de fidelidad al rey en las principales villas y ciudades del Nuevo Reino de Granada entre 1746 y 1812. En efecto, aunque la tradición de recibir al nuevo monarca con juras y fiestas data de la Edad Media, fue después de la transición de la dinastía Austria a la casa Borbón que el ritual de las juras se usó para fortalecer el vínculo entre el rey y los súbditos, toda vez que se inicia un proceso de propaganda y secularización de estos ceremoniales. El grado de obediencia que se le tenía al rey y la lealtad dependían en cierta medida de las situaciones específicas de cada territorio, pues la presencia de las instituciones de gobierno operaba más eficazmente en los centros urbanos que en los territorios de frontera, salvo en el caso de las sabanas de Tolú (región de la gobernación de Cartagena) en 1812 (Martínez y Gutiérrez, 2010, pp. 9-78). ${ }^{4}$

${ }^{3}$ Para una revisión de los estudios sobre juras en el Nuevo Reino de Granada véanse Georges Lomné (2003); Marcos González Pérez (1997); Daniel Gutiérrez Ardila (2009); Magali Carrillo (2010), y Julián Velasco Pedraza (2011).

${ }^{4}$ Para este momento, en el territorio de las llanuras del Caribe hubo un incremento de las juras que se explica por el apoyo recibido por el comandante de armas José Guerrero Cavero y los curas de las parroquias y pueblos de las sabanas de Tolú, el Sinú y las Montañas de

\section{(1) (1)}


Ahora bien, con la difusión de las ideas ilustradas, los cabildos del Nuevo Reino de Granada buscaron emular el ceremonial de la etiqueta de las Cortes europeas, modificando la eficacia simbólica del ceremonial y los rituales al finalizar el siglo XVIII.

\section{LAS JURAS DEL NUEVO REINO DE GRANADA}

Desde el siglo xvI, las fiestas religiosas y las civiles se usaron como un instrumento para comunicar ambos lados del Atlántico. La monarquía enviaba disposiciones sobre cómo debían celebrarse las fiestas. Así, en los territorios de Indias se celebraban los triunfos de la monarquía española y se hacían rogativas y abstenciones cuando los acontecimientos no eran favorables. Pero las celebraciones políticas que más realce alcanzaron en el Nuevo Reino de Granada fueron las juras para proclamar, recibir y celebrar el ascenso al trono de un nuevo monarca. Entre 1747 y 1812 los monarcas españoles fueron jurados y proclamados por los vecindarios locales en festejos que organizaban los cabildos y en los que sobresalía la participación del alférez real y el patriciado local. Sin embargo, las celebraciones y fiestas en honor a la monarquía se hacían no sólo por el fallecimiento del rey y el ascenso al trono de un nuevo monarca, sino también con ocasión de la fiesta del santo patrono del rey, los matrimonios de la casa real, el nacimiento de las infantas y los príncipes y las celebraciones de sus cumpleaños. En efecto, el cambio de dinastía en la casa real a comienzos del siglo XVIII no sólo posibilitó las transformaciones políticas, económicas y sociales, sino que hizo de las juras un ritual cohesionador de las relaciones entre el rey ausente y los vecindarios locales. Las juras, como mecanismo de cohesión de los lazos entre la monarquía y los súbditos, fueron adquiriendo mayor importancia a medida que avanzaba el siglo XVIII y alcanzaron su máximo clímax en 1808, con la crisis que se desató con los acontecimientos de Bayona. La suntuosidad y el realce que sufrieron los ceremoniales de las juras al rey en el siglo xviII obedecían a una mayor inversión económica en la fiesta como tal, al aumento de días dedicados a los regocijos y la festividad, y a las trasformaciones políticas que llevaron al régimen borbón a introducir un conjunto de reformas y coacciones externas

María -los tres núcleos de poblamiento de don Antonio de la Torre y Miranda-, quienes por su fidelidad al rey Fernando VII se negaron a jurar obediencia a la Constitución de Cartagena y a sus autoridades (Martínez y Gutiérrez, 2010, pp. 42-71).

\section{()(1) $\$$}


que, lentamente, se transformaron en autocoacciones (Elias, 2012, p. 123). Tanto las disposiciones jurídicas emanadas del rey por medio de reales cédulas y órdenes reales como los acuerdos emanados de los cabildos cumplieron dos tareas fundamentales: mantener la seguridad del reino como protector y símbolo de orden y hacer del ceremonial de las juras un elemento de distinción, transformando las celebraciones y fiestas en un espectáculo del que todos ansiaban participar (Pita Pico, 2016, p. 27). Y aunque el ceremonial de las juras era una carga pesada para todos los participantes operaba también como un motor infatigable que los impulsaba hacia adelante en una compleja red de interdependencias en las que las necesidades de reconocimiento y prestigio social ponían en franca rivalidad a los agraciados y los excluidos (Elias, 2012, pp. 117-118). En tal sentido, las juras eran, para los habitantes del Nuevo Reino de Granada, una forma de reafirmar la lealtad, la obediencia y la fidelidad como súbditos de su majestad. La obediencia era demostrada, en primer lugar, en la celebración de las exequias de los reyes, guardando luto y siguiendo las pautas del ritual. Pero fue sólo a partir de la jura de recibimiento de Carlos IV que este tipo de rituales alcanzó un patrón más homogéneo y continuo. Hubo casos como el de Josep de Acosta, peninsular y capitán de milicias del valle de San Miguel de la Guaduas, quien el 6 de enero de 1790 aprovechó la jura de recibimiento de Carlos IV para solicitarle al rey que se le concediera a esa población el título de villa y a él el de alférez real. ${ }^{5}$ Para acceder al título, no sólo ofreció costear todos los gastos de la jura, sino que también acudió a un ritual previo, en medio de la junta que había constituido el vecindario para esa ocasión. Una vez estuvo entre los asistentes, se puso de pie y sobre una mesa dispuesta con dos velas encendidas y con el libro de los santos evangelios encima, colocó su mano izquierda sobre ellos y la derecha sobre la cruz de su espada, hincó una rodilla y juró ante los asistentes cumplir con las funciones de alférez y representar a los vecinos en la ceremonia de recibimiento del rey. ${ }^{6}$ El ritual fue repetido por los miembros del Cabildo, el clero y los vecinos distinguidos. Acto seguido, se procedió al paseo público hasta llegar al tablado que se había dispuesto en la Plaza Mayor. Encabezaba el desfile José de Acosta montado en su caballo y acompañado por cuatro bastidores que le abrían camino y otros tantos que lo custodiaban. Subió al tablado, pidió silencio y dijo: "escuchad, atended, oíd. Esta villa de san Mi-

${ }^{5}$ Josep de Acosta solicita el título de Alférez Real. Fondo Virreyes. T. 1, fs. 4r.-4v. Archivo General de la Nación (en adelante AGN), Bogotá, Colombia.

${ }^{6}$ Fondo Virreyes. T. 1, fs. 17v.-18r. AGN, Bogotá, Colombia.

\section{(1)(1)}


guel de Guaduas por el rey don Carlos IV, que Dios guarde, rey de España y de las Indias". ${ }^{7}$ En medio de la nubosidad y la amenaza de un aguacero, el desfile continuó hasta llegar al templo de los franciscanos en donde se repitió la jura. Siguieron nuevamente a la casa del alférez, quien allí ofreció un refresco para todos los asistentes. En las primeras horas del día siguiente se celebró la misa de acción de gracias y tedeum laudamus. Los regocijos de plaza, corridas de toros, luminarias, pólvora y demás diversiones se extendieron por otros cuatro días consecutivos en los que esta pequeña población hizo de la jura el espectáculo para sobresalir ante la villa de Honda y la ciudad de Santa Fe. En este caso, merecen atención dos aspectos: primero, el ofrecimiento y la celebración de la jura como actos encaminados a conseguir los títulos de villa y alférez real; y segundo, la puesta en escena de un ritual en una zona poblada en su mayoría por labradores, que servía como "garganta del comercio" entre la capital del Nuevo Reino y la villa de Honda. ${ }^{8}$ Sin duda, el acto por medio del cual el vecindario de Guaduas revistió a Josep Acosta de la legitimidad de alférez real, sin que hubiese recibido el título, da cuenta de una temprana apropiación del vecindario de esa población de la "reasunción soberanía primitiva", generalizada por muchos de los cabildos del Nuevo Reino en la coyuntura de la independencia (Gutiérrez Ardila, 2010, pp. 343-360; Martínez Garnica, 2007, pp. 286-333; McFarlane, 2009, pp. 31-59). Sin duda, el vecindario de esta población cercana a la ciudad de Santa Fe buscó atribuirle una doble función a la jura: mantener la tradición de agasajar al rey y aprovechar el momento para ganar independencia ante la villa de Honda, reclamando el título de villa para la población de Guaduas, logrado sólo 20 años después, dentro de la coyuntura política de las independencias (Gutiérrez Ardila, 2010, p. 348).

\section{LOS ALFÉRECES Y LAS JURAS}

Aproximaciones como la de Alfonso Rubio Hernández (2010) muestran que la proclamación pública de los pregoneros en el mundo colonial acontecía en la Plaza Mayor, espacio connotado simbólicamente donde se realizaba la mayoría de los rituales religiosos y cívicos, así como las fiestas de advocaciones locales y juras en honor al rey. Es importante precisar que la función de los

${ }^{7}$ Fondo Virreyes. T. 1, f. 20v. AgN, Bogotá, Colombia.

${ }^{8}$ Fondo Virreyes. T. 1, fs. 1r.-24r. AgN, Bogotá, Colombia.

\section{()(1) $(2$}


pregoneros sufrió modificaciones entre los siglos XVII y XVIII. Primero estuvo asociada con la difusión de las decisiones de la administración de justicia y luego, a medida que avanzó el siglo XVIII y se cristalizó la representación de las juras de recibimiento de los reyes, se restringió a los anuncios de los acontecimientos locales: remates en pública almoneda, edictos y subastas públicas. En cambio, los alféreces alcanzaron mayor protagonismo en el siglo xVIII, al fungir como figura central en las celebraciones de carácter político, como fue el caso de los alféreces de Santa Fe, Santa Marta, Cartagena, Popayán, Simití, Honda, Cali y Buga durante las juras al rey, luego de las abdicaciones de Bayona, según lo han mostrado Jiménez Meneses (2007), Prado Valencia (2008) y Gutiérrez Ardila (2009).

A diferencia del siglo xviII, cuando la noticia por la muerte del rey demoraba más tiempo en ser conocida por los cabildos del Nuevo Reino de Granada, en 1808 los acontecimientos tardaban pocos meses para ser recibidos, debido a una mayor eficiencia en las comunicaciones entre las poblaciones del Nuevo Reino y la península. En Popayán, por ejemplo, el 9 de julio de 1808 el teniente de gobernador don Manuel Santiago Vallecilla se dirigió al Cabildo para informar sobre la abdicación del rey Carlos IV en su hijo Fernando VII. ${ }^{9}$ La noticia se difundió entre el vecindario y a las tres de la tarde los miembros del Cabildo se presentaron a caballo en la Plaza Mayor, como muestra de su apego a la hispanidad y su disposición para defender con su vida al monarca. ${ }^{10}$ El luto por el destino del rey no se hizo esperar: al otro día, los cuerpos civil y eclesiástico se sumaron al acontecimiento, al presentarse en la Plaza Mayor con trajes negros; en los días siguientes se celebraron las misas respectivas para solicitar la ayuda divina y se hicieron los preparativos para la celebración de la jura. Pero las intenciones y las lealtades profesadas no se correspondían con las necesidades terrenales del Ayuntamiento, que debía resolver los problemas del abasto de alimentos, sortear las inclemencias del invierno y afrontar las diferencias entre su elite local. Esta elite consideraba que la decisión sobre la fecha para celebrar la jura era del gobernador Miguel Tacón, quien se hallaba ausente. ${ }^{11}$ El alférez don Manuel

${ }^{9}$ Cabildo del 9 de julio de 1808. Fondo Cabildo. T. 53, Libro de 1808, fs. 13r.-13v. Archivo Central del Cauca (en adelante Acc), Popayán, Colombia.

${ }^{10}$ Cabildo del 9 de julio de 1808. Fondo Cabildo. T. 53, Libro de 1808, f. 13v. Acc, Popayán, Colombia.

${ }_{11}$ Cabildo del 9 de julio de 1808. Fondo Cabildo. T. 53, Libro de 1808, f. 17v. ACC, Popayán, Colombia.

\section{(1)(1) $\$$}


Antonio Tenorio y Carvajal ${ }^{12}$ consideraba que debía hacerse pronto, en tanto que el resto de los cabildantes, al tiempo que hacían oraciones y rogativas como fieles súbditos y buenos cristianos, preferían esperar el regreso del gobernador y las instrucciones del virrey ${ }^{13}$ Pero pronto el gobernador anunció su regreso y el debate se centró en cómo se debía hacer la demostración de amor y lealtad al rey, pues decían estar dispuestos a sacrificar sus vidas y haciendas, y a realizar "oraciones y rogativas públicas tanto en la Catedral como en las demás iglesias". ${ }^{14}$ Así, el 29 de octubre de 1808, los miembros del Cabildo, presididos por el gobernador -quien insistía en defender "la cabeza de la Monarquía”, a pesar de que se encontrara privada de su cuerpo- $-{ }^{15} \mathrm{y}$ el comisionado don Rafael Vicente Bourman, pasaron a la casa del alférez para acompañar la conducción del pendón real hasta la sala capitular, donde se congregaban el señor provisor y vicario general, los señores del venerable deán y Cabildo, el cura rector del seminario, los prelados de las órdenes regulares y los administradores de las reales rentas ${ }^{16}$ En otros puntos de la ciudad, el vecindario esperaba el clímax de la jura y los actos de plaza. El ceremonial seguía rigurosamente las pautas trazadas en 1790, con ocasión de la jura de recibimiento y aclamación del rey Carlos IV.

La mayor preocupación del ceremonial consistía en definir a quién se debía preferir en el acto mismo, si al alférez real o al alcalde ordinario. También se discutía si debía sacarse el pendón real con ocasión de la misa de acción de gracias. Hasta ese momento, por los menos en Popayán, no existía la costumbre de la misa de acción de gracias. Se decía que tal decisión apuntaba "a la justa consideración de no multiplicar actos que pudieran ocasionar desavenencias" y se reservaba la misa sólo para celebrar el cumpleaños del rey y los príncipes. Otro aspecto en los cambios introducidos al ritual con la llegada de Carlos IV estaba relacionado con que, el mismo día de la misa

12 Don Manuel Antonio Tenorio y Carvajal era hijo legítimo del alférez y regidor don Joseph Tenorio y de doña Teresa Carvajal Bernaldo de Quiroz. Su padre, al momento de otorgar su testamento, el 12 de diciembre de 1781, declaró que a su hijo "le tenía hecha cesión, y donación del empleo de Alférez Real”. Cf. Testamento de don Joseph Tenorio, 1781. Fondo Notaría primera. T. 51, 1781-I, f. 160r. ACC, Popayán, Colombia.

${ }^{13}$ Jura de Fernando Séptimo. 20 de septiembre de 1808. Fondo Cabildo. T. 53, Libro de 1808, fs. 17r.-17v. ACC, Popayán, Colombia.

${ }_{14}$ Jura de Fernando Séptimo. 20 de septiembre de 1808. Fondo Cabildo. T. 53, Libro de 1808 , fs. 25r.-25v. ACc, Popayán, Colombia.

${ }^{15}$ Jura de Fernando Séptimo. 20 de septiembre de 1808. Fondo Cabildo. T. 53, Libro de 1808, fs. 26r.-30r. ACC, Popayán, Colombia.

${ }^{16}$ Jura de Fernando Séptimo. 20 de septiembre de 1808. Fondo Cabildo, t. 53, Libro de 1808, fs. 17r.-26v. ACC, Popayán, Colombia.

\section{()(1) $\$$}


de acción de gracias se pusiera un retrato del rey en el balcón del Cabildo, el cual debía mantenerse hasta que concluyeran las fiestas y regocijos públicos. Además, en el acto de proclamación y jura los dos alcaldes ordinarios debían acompañar al alférez real "subiendo a los tablados". En el acto del juramento que se debería hacer en la sala capitular "habían de concurrir a ella todos los miembros del cabildo eclesiástico y demás prelados de las religiones" y que a la hora de la concurrencia "no ha de estar presente el Ayuntamiento, reservando a dos regidores y el aguacil mayor para que los recibiesen e introdujesen en ella, omitiendo pasar a la casa del alférez real en compañía de los demás señores”. Sin embargo, ante la incapacidad de los cabildantes para decidir sobre el ritual que acompañaba a la jura, el gobernador decidió que los dos regidores reservados para acompañar al Cabildo eclesiástico y demás prelados debían presenciar el juramento, por la

atención que se merecen estos cuerpos, como porque son todos actos de una misma función, es preciso conminarlos sin separarse de las reglas de la política y, finalmente, porque en nada se le perjudica al señor alférez real habiendo de ir a sacarlo de su casa todos los individuos // de este Ilustre cabildo y acompañarle también posteriormente los dichos dos señores regidores, evacuado el acto del juramento. ${ }^{17}$

Finalmente, el protocolo indicó que una vez el gobernador llegara a la casa del alférez real, este debía recibirlo con el pendón real en sus manos, y juntos irían hasta el recinto del Cabildo, donde estarían reunidos los demás cuerpos de la ciudad. En efecto, los protagonistas partieron de la casa del alférez y se pasearon por las calles, mientras el vecindario observaba y rumoreaba sobre la suerte del rey, las lealtades que compartían con los agraciados del ceremonial y los nexos que los unían con la metrópoli, a pesar de las distancias. Ingresaron a la casa del gobernador, dispuesta como recinto del Cabildo por la carencia de un edificio para este ceremonial y las reuniones de sus miembros, y allí los agraciados juraron su lealtad hacia el monarca. El alférez tomó la palabra y dijo:

hago pleito y homenaje una, dos, y tres veces, una, dos y tres veces, una, dos y tres veces según fuero y costumbre de España, y juro por Dios Nuestro Se-

${ }_{17}$ Cfr. Cabildo del 12 de enero de 1790. Fondo Cabildo. T. 36, Libro de 1790, fs. 8r.-11v. Acc, Popayán, Colombia.

\section{()(1) $\$$}


ñor; por esta Señal de Cruz y de estos Santos Evangelios de rendir vasallaje, prestar fidelidad, y guardar obediencia al Señor Don Fernando Séptimo, y reconociéndole por nuestro Rey, y señor natural, y a su nombre en las actuales circunstancias a la Real Junta de Sevilla, que nos gobierna a su nombre, protestando sacrificar vidas, y haciendas por su Soberanía. Ygualmente juro salir a hacer en público la proclamación con toda fidelidad, y circunspección [...].

Dijo el Señor Alférez Real que con el bastón que tenía en la mano había jurado su padre don José Tenorio al Señor Don Carlos // Tercero, que con él juró al Señor Don Carlos IV y ahora al Señor Don Fernando VII, por lo que quería que el Señor Comisionado Don Rafael Bourman lo llevare al Excelentísimo Señor Virrey para que su excelencia lo dirigiere a la Suprema Junta de Sevilla como un testimonio del amor y fidelidad a la Real persona de su Majestad. ${ }^{18}$

Al asociar el bastón distintivo del alférez real con el ceremonial de las juras pasadas en honor de Carlos III y Carlos IV, se buscaba transmitir el mensaje de lealtad y los vínculos que habían existido entre la familia Tenorio y la ciudad de Popayán. Según se dijo, el representante del virrey debía llevar el bastón al señor Amar y Borbón para que fuera enviado a la Junta Suprema como símbolo más claro del amor y de la fidelidad con que las autoridades y el vecindario de Popayán loaban al rey en estos difíciles momentos. En el desplazamiento entre la casa del alférez real y el recinto del Cabildo y entre este edificio y el templo y la Plaza Mayor, el alférez real, los cabildantes, el gobernador, el procurador y el delegado del virrey siguieron el orden establecido por el Cabildo desde 1791, según el cual se debían respetar las jerarquías, estar en silencio, seguir detrás del pendón real hasta llegar al recinto de la catedral y, una vez allí, ocupar el escaño que cada uno tenía reservado dentro del templo. Con las naves de la catedral como fondo, el ritual semejaba "un teatro de jerarquías terrenales y una disposición divina de las cosas" (Prado, 2008 , p. 40), con lo que se le trazaba al pueblo la pedagogía tripartita del poder: rey, Dios y pueblo. Una vez en la catedral, se realizó la misa de acción de gracias y al final se hizo el canto del tedeum, con muestras de devoción y humildad, esperanzados en que esto serviría para devolverle el trono al monarca y aliviar el dolor del vecindario de esta ciudad que, por siglos, había sido noble y leal a su rey. Al salir del templo hacia la Plaza Mayor, la muchedumbre se agolpaba sobre los cabildantes, ansiosa por ver el juramento y el

${ }^{18}$ Cabildo de 29 de octubre de 1808. Fondo Cabildo. T. 53, Libro de 1808, f. 25v. ACc, Popayán, Colombia.

\section{()(1) $(3$}


esperado lanzamiento de las monedas. El alférez real, acompañado de los dos alcaldes ordinarios, subió al tablado, ${ }^{19}$ repitió el discurso e increpó a la muchedumbre para que respondiera tres veces consecutivas "iViva el rey!". Luego, se derramaron sobre la multitud las monedas mandadas a acuñar con el rostro del soberano. ${ }^{20} \mathrm{El}$ momento tan esperado para el vecindario había llegado. Entonces, se podía oír entre la muchedumbre las voces de respaldo a la persona y la dignidad del monarca, cuyo retrato, que había sido elaborado por uno de los pintores de la ciudad, presidía el escenario. Al caer la tarde, el alférez real fue acompañado nuevamente hasta su casa y allí ofreció refrescos y comidas como muestra de la magnanimidad del rey al que representaba. El ceremonial de la jura le cedió su turno a los regocijos de plaza: tres días y sus noches se dispusieron para iluminar las calles, realizar corridas de toros y repique permanente de campanas. Para que tal acto no se olvidara, se mandaron a troquelar monedas de oro y plata con la efigie del rey, cuyas replicas fueron enviadas al virrey Amar y Borbón.

Desde mediados del siglo XVIII, la figura del rey se prestaba para ambigüedades. Al estar constituido por dos cuerpos, como se ha dicho, el acto de las juras centraba su atención en el cuerpo del rey como soberano de la monarquía y representante de una autoridad legítima. La permanencia del cuerpo legítimo del rey había que celebrarla con solemnidad y alegría para mantener la dinastía. Si el orden de los que gobiernan y los que rezan no le permitían al tercer orden (el de los que celebran) desfogar su tristeza y hacer un trance hacia el regocijo, la alegría, la celebración y la diversión, los vínculos entre el soberano y los súbditos podían debilitarse. Baste un ejemplo. En diciembre de 1810, en el barrio El Callejón de Popayán, fue herida la chichera Trinidad Lucano (mulata de 20 años), hija legítima del zapatero Joaquín Torres, alias "Pintingo". Por esto, el alcalde envió a la cárcel a José María, Pedro

${ }^{19}$ Cabildo del 29 de octubre de 1808. Fondo Cabildo. T. 53, Libro de 1808, f. 30v. Acc, Popayán, Colombia. El costo del tablado para la jura de Fernando VII fue de 23 pesos y siete reales, el cual costeó el Cabildo.

${ }^{20}$ El 20 de noviembre de 1808 los miembros del Cabildo le escribieron al virrey que Popayán había fijado como memorable este día acuñando una medalla que perpetuara y acreditara los sentimientos que animaban a sus habitantes. Se le informaba que: "al tiempo de colocarse V. M. sobre el trono, acababa un pobre oficial, Joaquín Cordero, de ductilirar la platina pura, sin conocimiento alguno de los metales usados en Europa, y a costa sólo de sus propios esfuerzos cuya circunstancia ha dado lugar a que se grave también el nombre de V. M. sobre este precioso metal de que es depositaria sola esta vuestra provincia. Esta fiel ciudad desea adquirir la gloria de haber perpetuado la memoria de su deseado monarca no sólo por medio de la plata y oro, sino de la // platina de sus propias Minas". Cf. Cabildo del 20 de noviembre de 1808. Fondo Cabildo. T. 53, Libro de 1808, fs. 40r.-40v. Acc, Popayán, Colombia.

\section{()(1) $\$$}


Parcos, Agustín López (mestizo, talabartero de 25 años) y Manuel José Vidal (vecino, sastre y mestizo de 18 años). El pleito había iniciado por el reclamo que Agustín le hizo a Antonio Muñoz por haberle matado una vaca, y luego este "se amotinó con Joaquín Torres y Antonio Quintero, y López fue desafiado por Joaquín Torres diciéndole que lo esperaba en El Callejón, en donde resultó herida Trinidad Lucano". ${ }^{21}$ Al ser atrapados, los implicados se resistieron, especialmente Agustín, quien provocó al alcalde diciéndole que "ya no había rey, que no existía el Señor Fernando VII, que por qué los llevaban presos, por ser pobres, cuando ya todos éramos unos, que así lo hubiera dicho un doctor y que lo reconociesen, que estaba en su entero juicio, y que por lo tanto se mantenía en lo dicho". ${ }^{22}$ En declaración días después, el alcalde comisario don José Antonio Balcázar le preguntó a López por qué había dicho esas palabras, y este respondió que había escuchado a su cuñado Pedro Pacos decir "que ya no había rey y que por lo tanto no se necesitaban soldados". ${ }^{23} \mathrm{Al}$ mismo tiempo, el doctor don Francisco Antonio Rodríguez, por súplica de Joaquín, solicitó al gobernador Tacón que lo liberara "por haber servido un año en la compañía de pardos con fidelidad". ${ }^{24}$ Esta riña evidencia, entonces, las ambigüedades con que se concebía la persona del rey en estos momentos de crisis, pues mientras que uno de los implicados argumentaba que no había rey y que no se necesitaban soldados, el otro solicitaba que se le dejara en libertad por haber sido fiel vasallo y para continuar al servicio del rey. El 22 de diciembre el gobernador Miguel Tacón liberó a Joaquín Torres, mientras que Agustín López permaneció en prisión.

\section{EL RITMO DE LAS JURAS}

Ahora bien, valga recordar que entre 1717 y 1812 en el Nuevo Reino de Granada se hicieron varias juras. En esta investigación he podido identificar 48 de ellas, las cuales tuvieron una duración de 104 días, repartidas de la siguiente

${ }^{21}$ Causa criminal contra Agustín y Manuel López por heridas que dieron a Trinidad Lucano. Sig. 5151 (Ind. J I-6 cr), fs. 1r.-2v. Acc, Popayán, Colombia.

${ }^{22}$ Causa criminal contra Agustín y Manuel López por heridas que dieron a Trinidad Lucano. Sig. 5151 (Ind. J I-6 cr), f. 3r. Acc, Popayán, Colombia.

${ }^{23}$ Causa criminal contra Agustín y Manuel López por heridas que dieron a Trinidad Lucano. Sig. 5151 (Ind. J I-6 cr), f. 6r. Acc, Popayán, Colombia.

${ }^{24}$ Causa criminal contra Agustín y Manuel López por heridas que dieron a Trinidad Lucano. Sig. 5151 (Ind. J I-6 cr), f. 12r. Acc, Popayán, Colombia.

\section{()ㅜ(1) $\$$}


manera: Fernando VI fue jurado dos veces en 1747 (4\%); Carlos IV, siete veces (14\%) entre 1789 y 1792; y Fernando VII, 40 veces (82\%) entre 1808 y 1812 (en 1808, quince veces; en 1810, dos; en 1812, 23). ${ }^{25}$ Esta muestra documental da cuenta de un aumento en la frecuencia en la celebración de las juras a partir de 1790, intensificada aún más a partir de 1808. En efecto, ya en 1808 el mensaje para el "pérfido Napoleón" no podía tener cabida para confusiones: Fernando VII contaba con el apoyo irrestricto de sus vasallos. El tiempo enseñaría qué tan firmes eran esas muestras de lealtad. La morfología de las juras estaba compuesta de bailes, juegos de azar, tablados, ofrecimientos de refrescos, salvas de artillería, fuegos, espectáculos taurinos, representación de obras de teatro, celebración de misas, cantos del tedeum e iluminación de las calles y la casa del Cabildo. En la celebración a Fernando VI, el ceremonial duró nueve días (9\%): dos en Panamá y siete en Popayán, y estuvo acompañada de fuegos, toros y teatro. A pesar de que fue la menos celebrada, el Cabildo de la ciudad de Popayán no escatimó en gastos con 22000 patacones: 8000 para fuegos, luminarias, máscaras, comedias y toros, y 14000 para adornos del solio, tablado de la jura, jaeces, convites y refrescos. ${ }^{26}$

La jura a Carlos IV duró 49 días (47\%): quince en Panamá, cuatro en Guaduas, cinco en Timaná, seis en la villa de Socorro, ocho en San Gil y once en la ciudad de Cali. El ceremonial estuvo acompañado de 19 días de toros, 21 días de teatro y catorce días de luminarias. Se repartió limosna a los pobres, en los hospitales y los conventos (48 toros y ocho terneros, en 584 pe-

${ }^{25}$ Esta información reposa en documentos que se encuentran en diferentes archivos. Del Archivo Histórico Nacional (AHN), Madrid: Fondo Estado. Leg. 58, docs. 25, 26, 27, 28, 1808; Leg. 54, doc. 1, fs. 1-16; Fondo Estado. Leg. 56 D, docs. 139, 140, fs. 5-14, 19v.-20v., 30r.33r., 39v.-47v., 55r.-58v., 67v.-68r., 71r.-75r.; Fondo Estado. Leg. 58, A, doc. 10, fs. 1-2, 1808. Fondo Estado. Leg. 58, A, doc. 16, fs. 1-11. Del AGN, Bogotá: Fondo Milicias y Marina. Leg. 47, fs. 646r.-v. y 651-656, 1747; Fondo Milicias y Marina. Leg. 77, fs. 418-428, 1808; Leg. 119, fs. 1001-1005, 1790; Fondo Milicias y Marina. Leg. 108, fs. 317-322 y 381-388, 1790; Fondo Policía. leg. 4, fs. 162-168, 1790; Fondo Milicias y Marina. Leg. 11, fs. 929r.-944v., 1808; Fondo Virreyes. T. 1, fs. 1-24, 1790; Sección Anexo. Fondo Historia. T. 3, fs. 555-564, 1791; Sección Archivo Anexo. Fondo Quejas. T. 1, fs. 107r.-122; Sección Colonia. Fondo Historia Civil. Rollo 20, t. 19, fs. 915-930. Del Acc, Popayán: Fondo Colonia, Sig. 9648 (Civil III-21-dt), fs. 8v.-35v., 1747. Del Archivo Histórico de Buga (АнВ), Buga, Colombia: Libros capitulares. T. 69, 1807. Del Archivo Histórico de Cali (AHC), Cali: Fondo Concejo. T. 28, fs. 225r.-229v. En el Archivo Histórico José Manuel Restrepo (AHJM), Bogotá: Fondo Archivos personales de José Manuel Restrepo. Rollo 2, vol. 2, 24 de septiembre de 1810; Revolución de Colombia. Documentos varios (17771815), fs. 40r.-41v.; Fondo I, vol. 14, fs. 34-35; 132-137; 162-166; 176-177; 182-183; 192. E Isidro Vanegas (2010). Durante los tres años de juras que se hicieron a Fernando VII las celebraciones se realizaron sobre todo entre los meses de septiembre y octubre (con 30 juras en total).

26 Sig. 9648 (Col-C III-21 dt), ff. 8v.-35v. Acc, Popayán, Colombia.

\section{(ㄷ)(1) $(3$}


sos), y a monjas y pobres vergonzantes (242 pesos). En la ciudad de Panamá, el 25 de enero de 1790 la proclamación de Carlos IV fue aplazada debido al fuerte invierno y la mayor parte de los capitulares suplieron el acto con un donativo de 1000 pesos enviados al monarca. Ese mismo año, el 29 de enero, en la ciudad de Cali, se gastaron 1200 pesos en la proclamación. En la villa de Timaná, el 11 de diciembre de 1792, el retrato del rey se mandó a pintar a Santa Fe. ${ }^{27}$

La jura a Fernando VII duró 46 días (44\%): dos en Honda; dos en Purificación; dos en Santa Fe; tres en Santa Marta, Buga, Girón, San Benito y Popayán; cuatro en Pamplona; ocho en Simití, y diez en Mompós. El ceremonial estuvo acompañado de once días de música, doce de exposición de las reales insignias, once de bailes, doce de salvas de artillería, 27 de misas y tedeum, y 24 de luminarias. Para tales majestuosas celebraciones, los alféreces solicitaron donativos. En Tunja, el 11 de octubre de 1808 se hizo un donativo de 252 pesos y el alférez real don José María Andrade solicitó al Ayuntamiento que coadyuvara con los gastos de la proclamación, el cual tuvo un valor de 78 pesos y dos reales. En la Villa de Santa Cruz de Mompós se donaron 1672 pesos en la celebración de un cabildo abierto; y en San Bartolomé de Honda, el 25 de diciembre de 1808 , se dio banquete a doce pobres de solemnidad y la asistencia a la jura fue de 3000 personas. ${ }^{28} \mathrm{El} 31$ de octubre de 1808 el Cabildo de Popayán se reunió para tomar decisiones sobre los donativos que debían hacer todos los súbditos, especialmente los funcionarios del gobierno y los vecinos más acaudalados. ${ }^{29}$ Pero la cicatería de los miembros del Cabildo, el gobernador y los agraciados era tan firme, como sus voces de fidelidad hacia el rey pronunciadas días anteriores, pues cada quien encontró las justificaciones que necesitaba y se ampararon en los gastos excesivos que había ocasionado la jura y los males dejados por una peste de langosta. ${ }^{30}$ Tomó la

${ }^{27}$ Fondo Historia. Sección Anexo. T. 3, fs. 555-564, 1791. AGN, Bogotá; Fondo Milicias y Marina. Leg. 119, fs. 1001-1005, 1790. AgN, Bogotá, Colombia; Fondo Policía. Leg. 4, fs. 162-168, 1790. AGn, Bogotá, Colombia; Fondo Cabildo. T. 28, fs. 225r.-229v. 1789. AHC, Cali, Colombia.

${ }^{28}$ Fondo Estado. 54-I, fs. 1-16, 1808. AHN, Madrid; Fondo Estado. 56-D, docs. 139-140, fs. 5-14, 19v.-20v., 30r.-33r., 39v.-47v., 55r.-58v., 67v.-68r., 71r.-75r. AHn, Madrid; Fondo Cabildo. Leg. 44, fs. 54r.-v., 64r. 78r. AнB, Buga, Colombia.

${ }^{29}$ Fondo Cabildo. T. 53, Libro de 1808, f. 26v. Acc, Popayán, Colombia.

${ }^{30}$ Cabildo del 31 de octubre de 1808. Fondo Cabildo. T. 53, Libro de 1808, fs. 27r.-28v. Acc, Popayán, Colombia. Desde el 10 de abril de 1806, el procurador del Cabildo de Popayán había expresado preocupación por la "necesidad de una rogativa pública con motivo de la plaga de langosta que nos amenaza y el rigor de las aguas". Dos años después, el regidor don José de Caldas se presentó ante el obispo para que "tuviera por conveniente se digne mandar

\section{()ㅜ(1) $\$$}


palabra el gobernador don Miguel Tacón y se despachó en todos los gastos que había hecho desde que salió de Europa, el establecimiento de su casa en Popayán y la visita a la Vega de Supía, en la que había tenido que "realizar gastos de consideración". Las excusas taponaron los bolsillos de algunos agraciados que, cinco días antes, manifestaron estar dispuestos a "sacrificar sus vidas y haciendas por la persona del rey". ${ }^{31}$ Al tiempo que lamentaban su pobreza, preparaban lo necesario para comenzar en el vecindario (al que llamaron en ese momento "Estado llano") la recaudación del dinero que enviarían a la metrópoli. Los tres cuarteles y El Ejido tendrían cada uno un religioso para acompañar la labor de los regidores encargados de recolectar el dinero. ${ }^{32}$ Con el discurso de fidelidad al rey y en presencia de los curas y de una proclama redactada por el doctor Ignacio Castro, los representantes del Cabildo comenzaron a recolectar el donativo.

Ahora bien, el ceremonial de lealtad a Fernando VII en Popayán se desarrolló en los contextos discursivo, simbólico y práctico. En el primero, se realizó con un escrito de lenguaje melancólico y poético -firmado como acta capitular, a pesar de ser de un autor particular-, con el cual el Cabildo asumió la pedagogía del ritual. Al pueblo llano se le invitó para que manifestara en el "semblante de su rostro los sentimientos del corazón". ${ }^{33}$

celebrar la misa, hacer la procesión y conjuro de la langosta en la capilla de Belén que quedó pendiente, desde los tiempos que se celebró la rogativa con este motivo". Cf. Carta del procurador al Cabildo, 1806. Fondo Cabildo. T. 51, Libro de 1806, fs. 8v.-9v. y 27r.-28r. AcC, Popayán, Colombia.

${ }_{31}$ El teniente de gobernador don Manuel Santiago Vallecilla ofreció la tercera parte de su sueldo, que era de 800 pesos, más 100 pesos por los años que durara la crisis. El alcalde ordinario de primer voto don Antonio de Arboleda dijo que, a pesar de los daños sufridos por la peste de langosta en su Real de Minas de Caloto, donaba 200 pesos y otros 200 por cada año de crisis. El alcalde ordinario de segundo voto don Manuel José Barona ofreció 200 pesos por una sola vez. El alférez real don Manuel Antonio Tenorio dio 25 pesos, debido a los crecidos gastos que había tenido en la celebración de la jura, y dijo que estaba dispuesto a "sacrificar sus bienes y su propia vida en obsequio de la soberanía". Cf. Cabildo del 31 de octubre de 1808. Fondo Cabildo. T. 53, Libro de 1808, fs. 26v.-28v. ACC, Popayán, Colombia. Se le hizo llegar también al virrey dos medallas de oro y cuatro de plata, de las que se habían mandado a acuñar para mantener la "memoria del rey", más una cajita con medallas para que fuesen enviadas a la Real Junta de Sevilla. Cf. Cabildo del 31 de octubre de 1808. Fondo Cabildo. T. 53, Libro de 1808, f. 41r. Acc, Popayán, Colombia.

${ }^{32}$ Cabildo del 31 de octubre de 1808. Fondo Cabildo. T. 53, Libro de 1808, fs. 29r.-29v. Acc, Popayán, Colombia.

${ }^{33}$ Cabildo del 31 de octubre de 1808. Fondo Cabildo. T. 53, Libro de 1808, f. 37r. Acc, Popayán. Colombia.

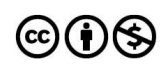


En la proclama que increpó al vecindario a contribuir económicamente para mantener la lealtad al rey se buscaba una eficacia simbólica similar a la que se conseguía con la jura:

Popayán: vuestros semblantes manifiestan los sentimientos del corazón. En ellos se ve la sorpresa y la aflicción, que ha días os devora. Os pensabais sobre flores, gozabais de tranquilidad en medio de la soberbia cordillera que os circunda. La América Española toda se inundaba en sangre humana. La coronación del amado Fernando presagiaba vuestra felicidad futura y de repente resuena entre nosotros el trueno asolador. Se os anuncia que el traidor, el vil Napoleón nos ha arrebatado a Fernando. Víctima de la hipocresía, falacia y perfidia, yace entre aquellas manos tendidas de sangre real. Su vida peligra, y ya los gritos de nuestros hermanos, elevados hasta el cielo, han herido vuestros oídos. Sabio gobierno. ¡Padres de la patria! (exclaman) ¿Qué es esto? ¿Dónde está nuestro centro, nuestro Rey, el amado Fernando? Y llenos de furor, con aquel valor característico del Español, sale el magistrado, y el soldado, el noble, y el plebeyo, el artesano, y el labrador; hasta el religioso deja su retiro, y las mujeres cambian sus ruecas por cuchillos: todos con la arma en la mano juran, marchan, devoran al tirano y rescatan al Rey. Toda la nación alarmada busca jefe que dirija sus acciones, y marcha a destrozar primero al soldado que bajo el título de amigo, está en su // casa: no reparan peligros, no temen amenazas, no los amedrenta la carnicería de Murat. Sin pólvora, sin municiones, sin caudales, pero llenos de Religión, fidelidad y entusiasmo, arrostran los ejércitos, $\mathrm{y}$ por medio de las balas y bayonetas clavan el cuchillo en esos corazones pérfidos. Desbaratan y derrotan, el Andaluz a Dupont, el Castellano a Murat, $y$ todas las provincias a un mismo tiempo, se arman, marchan, degüellan y llenan de terror a esas tropas alevosas repartidas en la nación. Errantes por las montañas se ocultan el furor Español, han visto por la primera vez, que los corazones animados de los deberes sagrados de la Religión, Patria y Rey son los que ponen barrera a la ambición, a aquella ambición que no respeta ni el templo del Altísimo, ni la cabaña del labrador. ${ }^{34}$

La proclama insistía en que los males derivados de la captura del rey serían nefastos para la península y sus reinos. La tranquilidad se vulneraría y correría la sangre de los americanos, se saquearían las casas, se violarían las

${ }^{34}$ Cabildo del 31 de octubre de 1808. Fondo Cabildo. T. 53, Libro de 1808, f. 37r. ACc, Popayán, Colombia.

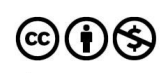


hijas y se profanarían los templos. Se atemorizaba a la población diciéndoles de los templos: "¿sufrirías ver dentro de ellos la algazara de soldados sin religión, avanzarse a los altares, derribar las imágenes, desnudarlas de sus joyas y poner sus manos sacrílegas en los vasos que sólo ha tocado la mano pura del Levita con la sangre del cordero? ¡Ah! Veo que te estremeces sólo de oírlo". ${ }^{35}$ Se invitaba a enfrentar al enemigo para salvar la patria y defender al rey. El llamado era por la unidad, la solidaridad y la defensa de la soberanía encarnada en el monarca.

En el contexto práctico, la jura daba cuenta de las diferencias entre patricios y plebeyos, los primeros como protagonistas y los segundos como espectadores. También evidenciaba la eficacia simbólica que habían alcanzado los actos de regocijo con los que se acompañó la jura. Hubo quienes expresaron, con apesadumbrado rostro, el amor que sentían por el rey, más fuerte ahora que se encontraba preso. Era claro que esto debía corresponder con un donativo, pero el dinero recaudado entre 94 personas fue apenas de 4427 patacones. ${ }^{36}$ De esta magnitud era la fidelidad del vecindario de Popayán por la vida y persona de Fernando VII.

Una situación similar se vivió en la ciudad de Buga, pues, al conocerse la noticia sobre la suerte del rey, el Cabildo programó la proclamación en honor de Fernando VII y el vecindario corrió hacia los templos para implorar la eterna misericordia de Dios. ${ }^{37}$ En esta ciudad patricia de hacendados, ganaderos y comerciantes la jura al rey se realizó el 4 de diciembre, acto al que fueron convocados 42 hombres "de los mestizos más apreciables" para que, en calidad de soldados, asistiesen a la función. A las tres de la tarde del 4 de diciembre de 1808 los miembros del Cabildo se presentaron en la casa del alcalde ordinario don Pedro Sánchez de Hoyos y, "montados en caballos aderezados con la mayor decencia", pasaron a la casa del alférez real don Nicolás de Ospina donde estaba colocado el retrato del rey, adornado con un marco de plata. En medio del acalde ordinario y el alférez real, el pendón real y el retrato del rey fueron conducidos a la casa de Cabildo. Por su parte, el vecindario se encontraba reunido en la Plaza Mayor "y ocupadas las ven-

${ }^{35}$ Cabildo del 31 de octubre de 1808. T. 53, Libro de 1808, f. 37v. Acc, Popayán, Colombia.

${ }^{36}$ Cabildo del 31 de octubre de 1808. Fondo Cabildo. T. 53, Libro de 1808, fs. 48v.-52r. Acc, Popayán, Colombia.

${ }^{37}$ Relación de lo que se ejecutó en la ciudad de Buga por disposición del muy ilustre Cabildo, con motivo de la augusta proclamación del señor don Fernando VII por rey de España e Indias, que se hizo el día 4 de diciembre de 1808, por órdenes superiores. 1807. Fondo Libros capitulares. T. 69, Libro de 1807, fs. 1r.-8r. Анв, Buga, Colombia.

\section{()(1) $(9$}


tanas y balcones de las casas del rededor dejándose admirar el silencio con el que todos esperaban el resultado de aquel acto" ${ }^{38}$ Una vez en el recinto del Cabildo, el alférez hizo el respectivo juramento poniendo las manos sobre los evangelios y en presencia del cuerpo eclesiástico de la ciudad, los miembros del Cabildo y los 42 vecinos mestizos, representantes del patriciado local. Seguidamente, el alférez pasó al balcón de la casa de Cabildo que daba a la Plaza Mayor e hizo la primera jura ante el pueblo, que la recibió con entusiasmo y alegría. Entonces, el regidor decano don José Vicente Serrano tomó en sus manos la imagen del soberano y con "una arenga corta y expresiva" hizo la jura, que por una sola voz fue correspondida por el pueblo con vivas, aclamaciones y movimientos, acompañado el acto por el repique general de campanas, descargas de pólvora, fuegos artificiales prevenidos por el alférez real y concierto de música, colocado del mismo balcón, en cuyas circunstancias manifestó su placer el citado regidor decano, arrojando al pueblo cantidad de pesos fuertes. Continuaron los actos en la "iglesia matriz" en donde se cantó el tedeum y se continuó el paseo por las calles principales, las plazuelas de la Ermita y Santo Domingo, hasta terminar en la Plaza Mayor en la que se hizo la última jura sobre el tablado dispuesto para tal fin. Pasaron luego a la casa del alférez real, quien ofreció refrescos y colaciones a los asistentes. En cada una de las proclamas, el alférez derramó sobre los asistentes puñados de monedas con la efigie del rey. A las cinco de la tarde concluyeron los actos y se dispusieron tres días con sus noches para celebraciones en las que reinó el alborozo popular y los más finos sentimientos de amor y lealtad al rey Fernando VII.

\section{FIEL SÚBDITO Y BUEN CRISTIANO}

La celebración del ascenso al trono de los monarcas con actos simbólicos de carácter religioso y político se inscribía en la tradición según la cual había que ser fiel súbdito y buen cristiano (Muir, 2001, pp. 289-308, 310-332), una razón que explica que el ceremonial de fidelidad al rey tuviera contenidos religiosos, como el himno del tedeum y la Eucaristía. Esta ambigüedad tam-

${ }^{38}$ Relación de lo que se ejecutó en la ciudad de Buga por disposición del muy ilustre Cabildo, con motivo de la augusta proclamación del señor don Fernando VII por rey de España e Indias, que se hizo el día 4 de diciembre de 1808, por órdenes superiores. 1807. Fondo Libros capitulares. T. 69, Libro de 1807, f. 3r. AнB, Buga, Colombia.

\section{()(1) $\$$}


bién se observaba en la celebración de algunas fiestas religiosas en zonas distantes de los centros de poder del Nuevo Reino de Granada. El 29 de marzo de 1784, el doctor don José Fernando Calvo, cura y vicario de la ciudad de Nuestra Señora de la Asunción de la Palma, denunció los excesos que se cometían en la celebración de las fiestas de la patrona y nombró como apoderado para llevar el pleito al doctor don Juan Antonio Ramírez. Al parecer, los costos y el sobresalto del ritual habían sido asimilados por el cura, para que se diera a conocer la situación ante la Real Audiencia. En el interrogatorio varias personas fueron llamadas a declarar. Antonio Zamudio manifestó que en los dos años en los que él había realizado fiestas había gastado 40 pesos en las de Iglesia, y cerca de 250 en toros, comedias, colaciones y licores. ${ }^{39}$ También acudieron a denunciar los excesos los vecinos del pueblo de Caparrapí, a quienes se les obligaba a costear los festejos de la ciudad de la Palma, sin que ellos entendieran por qué debían hacerlo. Así, José Rusique dijo que en 1781, cuando él celebró la fiesta, había gastado 70 pesos en asuntos de Iglesia, representados en cera, cebo, pólvora, víspera, día, sermón y alcalde, y que en las fiestas de plaza gastó de forma obligada 300 pesos. ${ }^{40}$ Los gastos de plaza se representaban en toros, botijas de aguardiente, meriendas y "convites a que es obligado el alférez desde el día diez de agosto hasta el último de dicho mes" ${ }^{41}$ Hasta aquí las fiestas de la Palma se mantenían dentro de lo que pasaba con otros regocijos en el Nuevo Reino de Granada. Pero cuando las autoridades llamaron a declarar a dos de los vecinos principales, don Ignacio de Liévano y Juan de Dios Linares, el proceso tomó otros matices, pues se dijo que no sólo se trataba de gastos excesivos y de que se comprometiera a toda la jurisdicción en la fiesta, en detrimento del culto divino, sino que se seguían algunas de las pautas del decoro que se usaban en las juras de recibimiento de los reyes. Lo más preocupante era el hecho de que, tres años antes, se eligieran cuatro vecinos como alféreces o priostes.

Para la celebración y culto en ellas, convida el Alférez a los señores eclesiásticos que se hallan en el lugar, a los Señores Justicia y Regimiento y vecinos distinguidos que todos compondrán el número de veinte o treinta, quienes pasadas las vísperas llevan al Alférez a su casa y este les corteja con un trago de vino o de aguardiente, dulce, chocolate y tabaco y al siguiente día estos

\footnotetext{
39 Fondo Historia Eclesiástica. T. 4, doc. 15, fs. 657r.-660r. AgN, Bogotá, Colombia.

40 Fondo Historia Eclesiástica. T. 4, doc. 15, f. 662r. AGN, Bogotá, Colombia.

41 Fondo Historia Eclesiástica. T. 4, doc. 15, f. 662r. AGN, Bogotá, Colombia.
} 
mismos convidados le vuelven a llevar (después de pasar la procesión, sermón y misa) a su casa en donde les da un almuerzo que no excede de tres o cuatro platos compuestos de las legumbres y carnes que el lugar produce. ${ }^{42}$

A finales del siglo xvin, los honores que se desprendían de la participación en las fiestas sólo estaban permitidos en las juras por el ascenso al trono de un nuevo monarca. Los beneficios y los excesivos gastos cada vez fueron más criticados por el clero y los funcionarios del gobierno, y esas pautas del decoro -expresados en el orden y el desfile- se dejaron sólo para las celebraciones civiles. Este cambio se explica, en buena medida, por la incidencia del Concilio de Trento en las fiestas y el ceremonial, y por un abandono paulatino de las pautas del honor y el decoro en los rituales religiosos para fortalecer el ceremonial civil de las juras, asociado con el sostenimiento de la soberanía en el cuerpo político del rey. En efecto, en la década de 1790, a partir del ascenso al poder del rey Carlos IV, fue que el ceremonial político de la jura siguió un orden y una etiqueta en la ejecución, y que se cristalizaron los tres órdenes de la celebración civil: el de los que gobiernan, el de los que rezan y el de los que celebran. Antes no se hacían mayores diferenciaciones y, por ello, las fiestas religiosa y civil se inscribían en el umbral de lo profano.

Otro caso donde se expresa la costumbre de mezclar los ceremoniales religioso y político era la villa de Mompós. El 18 de abril de 1765, el Cabildo registraba cómo para "la invención de la Santa Cruz" y la fiesta de San Sebastián se debía sacar el Pendón Real y

en la casa de el dicho Alférez Real adornado el balcón se coloca el Real Pendón a la vista pública y a la hora acostumbrada viene formado el cabildo a la casa de dicho Alférez Real a cuya puerta al lugar el cabildo se presenta el Alférez Real y se incorpora con el Real Pendón llevando a todos hasta el Señor Gobernador la preferencia pues se le pone a la derecha si va sin su teniente y de ir con este entra en el medio de los dos el Alférez Real y de esta suerte prosigue el cabildo hasta la Santa Yglecia Cathedral en la que se varía el orden tomando el primer asiento el Señor Gobernador como vice patrono Real y el segundo el Alférez Real en silla particular que se le pone con alfombras y el Pendón cerca de su persona, fixandose en una vara que allí a este fin se tiene preparada; recibe a un tiempo con el Señor Gobernador la paz saliendo para

42 Declaración de Juan Tomás Ramírez, de 60 años. 26 de agosto de 1784. Fondo Historia Eclesiástica. T. 4, doc. 15, f. 678r. AGN, Bogotá, Colombia.

\section{()(1) $(3$}


esto juntos el Sacristán Mayor que la lleva al vice patrono y el capellán del cabildo para el Alférez Real; y acabadas las funciones de la Yglecia, en el día y víspera vuelve el cabildo como vino con el Alférez Real hasta dexarle a la puerta de su casa, en donde entregando este el Pendón se torna a incorporar en el cabildo sin dicho Pendón en su lu //gar ordinario y va hasta la casa capitular donde se deshace el cuerpo de cabildo y allí convida a los compañeros para refrescar en su casa. ${ }^{43}$

Fue en contra de estas preeminencias del cabildo y de los alféreces que se opusieron parte de los reformadores en la segunda mitad del siglo XVIII, pues consideraban que se debía separar el lucimiento del pendón real y el reconocimiento del alférez de los actos de Iglesia. Por su parte, los clérigos, que antes de 1750 no atacaban estos reconocimientos en el ritual religioso, empezaron a quejarse de que la feligresía reclamaba un tratamiento similar al de los alféreces y que no había necesidad de tales distinciones, cuando el fin era la devoción y no el lucimiento de las diferencias estamentales y políticas. ${ }^{44}$ Estas ambigüedades dejan ver los matices que alcanzaron el ceremonial y la difusión de las maneras cortesanas de las Cortes europeas en los territorios de Indias.

\section{SOBERANÍA, INDEPENDENCIA Y LEALTAD}

La crisis imperial de 1808 se sintió en ambos lados del Atlántico. ${ }^{45}$ En poco tiempo, algunas palabras adquirieron nuevos sentidos y nociones como "patria”, "fidelidad", "público", "soberanía”, "pueblo”, "estado”, "revolución”, "independencia" y "constitución" comenzaron a ocupar un espacio sobresa-

${ }^{43}$ Fondo Competencias Bolívar y Panamá. T. 2, fs. 56r.-56v. 16 de junio de 1768. AgN, Bogotá, Colombia.

${ }^{44}$ Fondo Competencias Bolívar y Panamá. T. 2, f. 59v. 16 de junio de 1768. AGN, Bogotá, Colombia.

${ }^{45}$ Según Antonio Annino y Rafael Rojas (2008), "la nueva historia política partía del año decisivo de 1808, cuando el arresto de Carlos IV y Fernando VII en Bayona y la invasión napoleónica de España provocaron un vacío de poder en la Monarquía, que se tradujo en una intensa recuperación de la soberanía por parte de los cuerpos del antiguo régimen. El marcado interés en ese proceso de desplazamiento de la soberanía, entre el antiguo y el nuevo régimen, explica que buena parte de esa historiografía esté dedicada al análisis de la Constitución de Cádiz, de los procesos electorales que la misma introdujo en Hispanoamérica y a la recomposición territorial de los antiguos virreinatos" (p. 134).

\section{()(1) $(9$}


liente en los discursos con los que se proyectaba la utopía de la nación. ${ }^{46}$ Las críticas frente a la tiranía y al mal gobierno de los funcionarios borbónicos se fueron extendiendo como un letal virus por todo el territorio americano. Sin embargo, se trataba de una nueva concepción de los acontecimientos y las ideas, mas no de un cambio radical en las estructuras sociales, políticas y económicas del mundo colonial.

La sociedad se enfrentó a la sustitución de una administración imperial y una monarquía absoluta por un sistema constitucional y un ensayo de Estado nacional transatlántico, fundado en poderes electivos y representativos de una categoría nueva, el ciudadano, que buscaba la "reasunción de la soberanía primitiva" puesta en riesgo por la invasión del "enemigo francés". ${ }^{47}$ La materialización de este proceso se expresó en la reunión de los diputados en Cádiz. En los últimos meses de 1810 estaba formada la opinión sobre los asuntos de los que se ocuparían los miembros de la eclosión juntera: la elaboración de una constitución política ajustada a los tiempos, la supresión de las diferencias institucionales en la nación, la exigencia americana de fundar una representación en las Cortes sobre la base demográfica de los antiguos dominios y la pretensión de un gobierno doméstico en el que los americanos tuvieran una participación directa.

Aunque los logros de la Junta Central Suprema no fueron significativos y la conducción de la guerra contra los franceses resultó desastrosa, consiguió que se pensara que se "vivía en revolución", difundió la necesidad de reformas que acabaran con los privilegios coloniales y el despotismo, declaró el fin de la opresión de las colonias, incentivó la libertad de imprenta y encausó la reacción patriótica hacia lazos de solidaridad secular, pese a no lograr convertirla en solidaridad cívica. Pero lo más notorio fue que, al abrir una brecha con el mundo americano e impedir la formación de juntas similares a las peninsulares, prorrogó el sistema de gobierno colonial hasta 1810, cuando

${ }^{46}$ Sobre el lenguaje usado en los días previos a la crisis de 1808 y entre esta fecha y 1810 , Piqueras (2008) ha insistido en que: "Detrás de las palabras había conceptos, y tras estos, concepciones variables de los hechos, las situaciones y las ideas: un posicionarse ante una realidad que estaba cambiando a grandes pasos y en su movimiento se veía asistida por el protagonismo de actores sociales nuevos y, por ello, de perfiles todavía no bien definidos" (p. 6). Otros autores que han aludido a este problema son Jairo Gutiérrez Ramos (2008), Armando Martínez Garnica (2004) y Marco Antonio Landavazo (1999).

${ }^{47}$ El mejor estudio sobre este periodo en el Nuevo Reino de Granada es el de Daniel Gutiérrez Ardila (2010). Para otros trabajos que ayuden a comprenderlo, véanse Marco Palacios (2009), Gabriel Paquette (2009) y José A. Piqueras (2008).

\section{(이요}


ya era demasiado tarde, pues empezaban a nacer declaraciones de independencia absoluta.

Entre las reflexiones que desató la crisis imperial de 1808, cinco aspectos merecen atención: la discusión sobre el modo y la proporción de la participación americana en las instituciones que reasumirían la soberanía; la legitimidad de los nuevos y los antiguos poderes, y el estímulo de una conciencia criolla; la crítica al régimen colonial; el deseo de una autonomía territorial; y la articulación de ciudades y pueblos en torno a un proyecto político. No obstante, aunque esto generó esperanzas de cambios, no logró vulnerar del todo las estructuras del régimen colonial: por ejemplo, se evitó caer en una interpretación "exagerada" del concepto de libertad que eliminara la esclavitud y las diversas formas de sujeción. Del principio de igualdad de los ciudadanos se excluyó a esclavos, descendientes de africanos, sirvientes domésticos y personas sin modo de vida conocido.

Por ende, desde 1808 la vida política entró en constante agitación, exacerbada particularmente con las noticias que llegaban de la metrópoli y agudizada aún más con el arribo a Cartagena de Indias del enviado de la Junta de Sevilla José de Pando y San Llorente. Las tensiones entre la elite criolla y el gobierno virreinal se hicieron cada vez más agudas. En agosto de 1809 se instaló la primera junta autonomista de Quito, ejemplo que fue seguido por las demás ciudades y villas del Nuevo Reino (Gutiérrez, 2010).

Esta crisis, y su radicalización en 1810 con los gritos de independencia y la eclosión juntera, transformó las fiestas religiosas y abrió el camino a las celebraciones civiles y patrióticas (Pagán, 2001). La celebración religiosa se fue llenando de elementos patrióticos, y algunas festividades, como el Corpus Christi, la Santa Librada y la fiesta de la Virgen de Chiquinquirá, fueron resignificadas según los intereses de la república, las nuevas elites y los nuevos ciudadanos. Las celebraciones a Dios y a los santos incorporaron rituales y ceremonias en beneficio de la patria, el Estado y la libertad (Florido, 1812, p. 14).$^{48}$ No obstante, algunos siguieron fieles al monarca Fernando VII y le ofrecieron juras y reconocimientos que, a pesar de su exotismo, no lograron cambiar el orden de las cosas.

Para 1810 los acontecimientos estaban dados para el nacimiento de la primera república, y el 20 de julio marcó una nueva orientación. Con distintos objetos y rituales, las celebraciones religiosas se apropiaron de nuevos contenidos políticos y artísticos, hasta el punto de que fiestas como las de

\footnotetext{
${ }^{48}$ Fondo I. Vol. 4, fs. 116r.-118r. AHJM, Bogotá, Colombia.
}

\section{(1)(1) $\$$}


Navidad, Semana Santa y el Corpus Christi se usaron para fortalecer el ceremonial político. Años más tarde, la Virgen de la Peña, Nuestra Señora de Chiquinquirá, Santa Librada -"a quienes los chapetones tenían por señora y abogada de este reino" (Posada, 1922, p. 126)-, y las figuras de Jesús, María y José fueron usadas en Santa Fe por el bando patriota y el Cabildo para aglutinar al pueblo en torno a la causa que defendían. ${ }^{49}$

Durante la primera república los cambios fueron más drásticos por las convulsiones de la independencia, por lo que se necesitaron las fiestas religiosas y civiles para defender los intereses de la época (Martínez y Rincón, 2011). Otro tanto hicieron los ejércitos realistas, que vieron en los suntuosos templos una fuente de financiación. Por ejemplo, en 1815, el ejército realista dejó consternada a la población de la ciudad de Cartagena al incursionar en los templos; arrasar con altares, candeleros, ciriales, atriles, lámparas y el Santo Sepulcro, todos objetos elaborados en plata maciza; y apropiarse de diamantes, esmeraldas, láminas y capones de oro, perlas, custodias, cálices y patenas que habían sido conservados por siglos y usados en celebraciones religiosas, y que terminaron en el mercado de Jamaica sirviendo para comprar víveres y sostener a los ejércitos realistas (Posada, 1929, t. 2, p. 210).

\section{CONCLUSIONES}

Los rituales de las juras en el Nuevo Reino de Granada fueron una continuidad de las tradiciones europeas, expresados en los ceremoniales civiles y eclesiásticos. A partir de 1791 se estandarizó el contenido de la fiesta y se cristalizó la separación, tan esperada por el clero, entre las prácticas sagradas y las profanas. Las fiestas y actos que acompañaban las juras diferenciaron el momento en que participaban los cabildantes, los miembros de la Iglesia y el vecindario. Así, la figura del alférez real cobró mayor importancia al ser el protagonista de las ceremonias, el agasajado en los festejos y presidir el orden y el desfile en las calles, el recinto del Cabildo, la asistencia al templo para el tedeum y la ejecución de la jura en el tablado dispuesto en la Plaza Mayor. Luego vendría el tiempo para que el pueblo llano hiciera lo propio, participando en corridas de toros, juegos artificiales, bailes, representaciones teatrales y ejecución de instrumentos musicales.

${ }^{49}$ Fondo Libros raros y manuscritos. Mss., 2829, f. 1r. 6 de diciembre de 1814. Biblioteca Luis Ángel Arango, Bogotá Colombia.

\section{()(1) $\$$}


Hasta 1759 las juras para celebrar a los reyes, aunque no tuvieron mayor cobertura en las poblaciones del Nuevo Reino, se extendían por más de ocho días, como sucedió en las ciudades de Cali, Popayán y Panamá. La llegada al trono de Carlos III, aunque fue el gran reformador de los Borbones, no recibió una atención destacada por parte de los cabildos del Nuevo Reino de Granada y sería en cambio su hijo Carlos IV el mayor beneficiado de sus políticas y de la celebración de juras. En el plano local, las juras ponen de presente las dificultades económicas de los cabildos, a pesar de que la mayoría de sus miembros se esforzó por lucirse de la mejor manera para recibir a los nuevos monarcas. Hasta en los lugares más apartados del Reino se hacían ingentes esfuerzos para congraciarse con el rey, como se desprende de las juras de la población de Guaduas, en 1791, y las que se hicieron en Sabanas de Tolú, en 1812.

Como se desprende de la consulta de las fuentes manuscritas y bibliográficas, Fernando VII fue el rey más jurado en el Nuevo Reino de Granada, debido a la crisis que se desató en todo el imperio y sus colonias y a la coyuntura política de la independencia. Después de 1810 su figura fue, simultáneamente, amada y odiada. Las juras para proclamarlo se extendieron por todo el Nuevo Reino, pero se presentaron algunos regicidios, como lo han señalado las investigaciones de Jiménez Meneses (2007, p. 78), Prado Valencia (2008, pp. 96-97) y Gutiérrez Ardila (2014). Entonces, los actos de la jura operaron como ceremonias mitigadoras del dolor que despertó entre los súbditos el resquebrajamiento del pacto que habían mantenido con el rey. La medida siguiente consistió en reasumir la soberanía a través de los cabildos y la reclamación de sus derechos.

Finalmente, el contenido y la morfología de la juras fue variado y ambiguo, en tanto que el carácter instrumental que ellas adquirieron hizo que los cabildos aprovecharan esas coyunturas políticas para fortalecer y preservar el principio antiguo de la soberanía primitiva, ganar prestigio personal y jurisdiccional y defender los intereses de las elites locales. En las juras, patricios y plebeyos competían sin tregua por los privilegios en el orden y el desfile, por lucir los mejores trajes y hacer las mejoras obras en los palcos y doseles que adornaban las calles, el templo y la Plaza Mayor. Los desafortunados, es decir, los artesanos, los negros, los mulatos, los indios y la gente pobre, apenas alcanzaban a participar con decoro en la elaboración de piezas de arte efímero, arriesgar sus vidas en las corridas de toros y en hacer representaciones teatrales decentes para demostrar el fervor en sus corazones por el nuevo rey aclamado y jurado.

\section{()(1) $\circledast$}




\section{LISTA DE REFERENCIAS}

Annino, A. y Rojas, R. (2008). La independencia. México: FCE.

Calvo, T. (2005). La jura de Fernando VI en Guadalajara (1747): de la religión real a la festividad. Takwá, 8, 67-92.

Carrillo, M. (2010). Rey y reino en las juras de lealtad. Anuario de Estudios Bolivarianos, XVI(17), 57-77.

Carrillo, M. y Venegas, I. (eds.). (2009). La sociedad monárquica en la América Hispánica. Bogotá: Plural.

Duby, G. (1983). Los tres órdenes de lo imaginario del feudalismo. Barcelona: Argot.

Elias, N. (2012). La sociedad cortesana. México: FCE.

Florido, F. (1812). Sermón que en la fiesta de Santa Librada hecho en obsequio del excmo. señor presidente don Antonio Nariño por el ilustre Cabildo de la Villa de Bogotá, pronunció el P. L. Francisco Florido de la orden de San Francisco. Santafé de Bogotá: Imprenta de D. Bruno Espinosa.

González Pérez, M. (1997). Juras Borbónicas en Santafé de Bogotá. Revista Memoria, 1(2), 54-81.

Gutiérrez Ardila, D. (2009). La Alférez de Yolombó. Notas histórico-críticas a la novela de Tomás Carrasquilla. Revista Universidad de Antioquia, 297, 48-57.

Gutiérrez Ardila, D. (2010). Un Nuevo Reino. Geografía política, pactismo y diplomacia durante el interregno en Nueva Granada (1808-1816). Bogotá: Universidad Externado de Colombia.

Gutiérrez Ardila, D. (2014). Matar a un rey ausente. Los regicidios simbólicos durante el interregno neogranadino (1808-1816). Revista Economía y Política, I(2), 5-37. DOI: 10.15691/07194714.2014.005

Gutiérrez Ramos, J. (2008). La Constitución de Cádiz en la Provincia de Pasto, Virreinato de Nueva Granada, 1812-1822. Revista de Indias, 68(242), 207-224. DoI: http:// dx.doi.org/10.3989/revindias.2008.i242.640

Jiménez Meneses, O. (2007). El frenesí del vulgo. Fiestas, juegos y bailes en la sociedad colonial. Medellín: Universidad de Antioquia/Premios Nacionales de Cultura.

Kantorowicz, E. (1985). Los dos cuerpos del rey. Un estudio de teología política medieval. Madrid: Alianza.

Landavazo, M. A. (1999). La fidelidad al rey. Donativos y préstamos novohispanos para la guerra contra Napoleón. Historia Mexicana, 48(3), 493-521.

Lomné, G. (2003). Le list et la granade. Mise en scénce et mutation imaginaire de la suveraineté á Quito et Santafé de Bogotá (1789-1830) (Tesis de doctorado inédita). Universidad de Marne-la-Vallée, París.

\section{()ㅜ(1) $\$$}


Martínez Garnica, A. (2004). Las juntas neogranadinas de 1810. En A. Martínez Garnica y G. Bustos (eds.), La independencia en los países andinos: nuevas perspectivas (pp. 112-134). Quito: Universidad Andina Simón Bolívar/Organización de Estados Iberoamericanos.

Martínez Garnica, A. (2007). La reasunción de la soberanía por las juntas de notables en el Nuevo Reino de Granada. En M. Chust (coord.), 1808. La eclosión juntera en el mundo hispánico (pp. 286-333). México: Fideicomiso Historia de las Américas-FCE/ Colmex.

Martínez Garnica, A. y Gutiérrez Ardila, D. (eds.). (2010). La contrarrevolución de los pueblos de las Sabanas de Tolú y el Sinú (1812). Bucaramanga: Universidad Industrial de Santander.

Martínez Garnica, A. y Rincón de Reátiga, B. (2011). La puesta en escena de la representación festiva del 20 de julio. En O. Jiménez Meneses y J. D. Montoya Guzmán (eds.), Fiesta, memoria y nación. Ritos, prácticas y discursos, 1573-1830 (pp. 205-245). Bogotá: Universidad Nacional de Colombia.

McFarlane, A. (2009). La caída de la monarquía española y la independencia hispanoamericana. En M. Palacios (coord.), Las independencias hispanoamericanas. Interpretaciones 200 años después (pp. 31-59). Bogotá: Grupo Editorial Norma.

Muir, E. (2001). Fiesta y rito en la Europa moderna. Madrid: Editorial Complutense.

Pagán, E. A. (2001). El arte efímero y los pintores valencianos en la primera mitad del siglo xix: de la fiesta barroca a la fiesta político-patriótica (1802-1833) (II). Cuadernos de Arte Iconográfico, 10(19), 183-212.

Palacios, M. (coord.). (2009). Las independencias hispanoamericanas. Interpretaciones 200 años después. Bogotá: Norma.

Paquette, G. (2009). Visiones de la ruptura del imperio español. Revista de Occidente, $341,7-23$.

Piqueras, J. A. (2008). 1808: una coyuntura germinal. Historia Mexicana, 58(1), 5-29.

Pita Pico, R. (2016). Celebraciones políticas y militares en Colombia: de virreyes y monarcas al santoral de la patria. Bogotá: Academia Colombiana de Historia (Colección Biblioteca de Historia Nacional, vol. cLXxIv).

Posada, E. (1922). Faustos de Santafé. Boletín de Historia y Antigüedades, 14(158), 123-128.

Posada Gutiérrez, J. (1929). Memorias histórico-políticas (t. 2). Bogotá: Imprenta Nacional.

Prado Valencia, D. F. (2008). Tensiones en la ciudad. Popayán 1808-1822 (Tesis de licenciatura inédita). Universidad del Cauca, Popayán.

Rodríguez Moya, I. y Mínguez Cornelles, V. (2012). Cultura simbólica y fiestas borbónicas en Nueva Granada. De las exequias de Luis I (1724) a la proclamación

\section{(ㅇ)(1) $\$$}


de Fernando VII (1808). Revista Ciencias Sociales, 9, 115-143. DoI: http://dx.doi. org/10.18046/recs.i9.1204

Rubio Hernández, A. (2010). La ley en el archivo. Representaciones de poder en los cabildos coloniales de Nueva Granada. Historia Crítica, 42, 10-35. DoI: http://dx. doi.org/10.7440/histcrit42.2010.02

Vanegas, I. (ed.). (2010). Plenitud y disolución del poder monárquico en la Nueva Granada. Documentos, 1807-1819. Santander: Universidad Industrial de Santander.

Velasco Pedraza, J. (2011). Celebrar el poder: juras y proclamaciones en el Nuevo Reino de Granada, 1747-1812. En O. Jiménez Meneses y J. D. Montoya Guzmán (eds.), Fiesta, memoria y nación. Ritos, símbolos y discursos, 1573-1830 (pp. 107-129). Bogotá: Universidad Nacional de Colombia.

\section{OTRAS FUENTES}

Archivos

Acc Archivo Central del Cauca, Popayán, Colombia.

AGN Archivo General de la Nación, Bogotá, Colombia.

AнB Archivo Histórico de Buga, Buga, Colombia.

AHC Archivo Histórico de Cali, Cali, Colombia.

АHJM Archivo Histórico José Manuel Restrepo, Bogotá, Colombia.

AHN Archivo Histórico Nacional, Madrid, España.

Bibliografía

Mínguez, V. (2007), La ceremonia de jura en la Nueva España. Proclamaciones fernandinas en 1747 y 1808. Varia Historia, 23(38), 273-292. 